\section{ВЗАИМОСВЯЗЬ ГЕМОДИНАМИКИ СОННЫХ АРТЕРИЙ ПРИ ХРОНИЧЕСКОЙ ОБСТРУКТИВНОЙ БОЛЕЗНИ ЛЕГКИХ С КОМПОНЕНТАМИ МЕТАБОЛИЧЕСКОГО СИНДРОМА}

В настоящее время вопросы диагностики и лечения хронической обструктивной болезни легких (ХОБЛ) подвергаются значимым изменениям: происходит расширение диагностических критериев, изучается влияние коморбидной патологии на течение и прогноз данной нозологии. По данным Всемирной организации здравоохранения, ХОБЛ занимает 4-е место среди причин смертности населения земного шара $[2,4,8$, 9]. У больных с ХОБЛ наблюдается возрастание числа случаев смертности от заболеваний сердечно-сосудистой системы, что позволяет предполагать важную роль сосудистых катастроф в патогенезе фатальных обострений ХОБЛ [1, 3, 5]. Среди многочисленных сопутствующих заболеваний ХОБЛ на сегодняшний день рассматривается сердечнососудистая патология, абдоминальное ожирение и дислипидемия [6, 7, 11]. Увеличение распространенности случаев абдоминального ожирения среди больных ХОБЛ может быть связано с уменьшением физической активности, курением, снижением чувствительности к инсулину. Установлено, что наличие ожирения у больных ХОБЛ приводит к ограничению физической активности пациентов и возрастанию частоты госпитализаций $[4,9,10]$. Интересно отметить, что фактор некроза опухоли-альфа (ФНО- $\alpha$ ) на сегодняшний день является одним из основных факторов, связывающих системное воспалениеприХОБЛсосновнымкомпонентом метаболического синдрома - ожирением по абдоминальному типу [9, 11]. Изучение состояния гемодинамики магистральных сосудов при ХОБЛ, ассоциированной с абдоминальным ожирением, позволит совершенствовать методы профилактики и лечения осложнений данной патологии.

Цель исследования: изучить влияние компонентов абдоминального ожирения на изменения гемодинамики в сонных артериях у больных с ХОБЛ и оценить их взаимосвязь с инсулинорезистентностью, липидным спектром, антропометрическими данными.

\section{Материалы и методы}

В комплексное исследование включено 63 пациента в возрасте от 37 до 69 лет со среднетяжелой стадией ХОБЛ в сочетании с абдоминальным ожирением (1-я группа). Объем талии у мужчин в среднем равен $107,3 \pm 4,61$ см, у женщин $-103,1 \pm 4,81$ см. Коэффициент объема талии к объему бедер у мужчин составил 1,12 $\pm 0,06$, у женщин $1,07 \pm 0,04$. Абдоминальный тип ожирения I степени диагностирован у 23 пациентов (36,5\%), II степени - у 21 (33,3\%), III степени - у 19 больных (30,2\%). Во 2-ую группу вошли 25 пациентов с изолированным течением ХОБЛ с индексом массы тела (ИМТ) 18,5-24,9 кг/ м2, сопоставимых с группой исследования по возрастным и функциональным характеристикам. В контрольную (3-ю группу) вошли 19 здоровых добровольцев с нормальными антропометрическими данными. Клиническая характеристика рассматриваемых групп больных представлена В таблице 1. Уровень эндотелина-1 определялся методом иммуноферментного анализа с высокой чувствительностью с использованием тест-систем фирмы BIOMERICA (Австралия). Исследование содержания фактора некроза опухолиальфа (ФНО- $\alpha)$ осуществлялось с помощью тест-систем ЗАО "Вектор-Бест» методом иммуноферментного анализа. С помощью расчета индекса инсулинорезистентности (ИИР) по критерию, описывающему степень инсулинорезистентности (The Homeostasis Model Assessment - HOMA), изучали чувствительность тканей к инсулину [6, 9]. Оценивалось содержание в крови общего холестерина, холестерина липопротеинов

Резюме В статье рассматривается проблема изучения особенностей состояния гемодинамики в сонных артериях при коморбидном течении хронической обструктивной болезни легких (ХОБЛ) и абдоминальном ожирении. Интересно отметить, что при коморбидном течении ХОБЛ наблюдается более выраженное повышение показателя индекса резистентности на уровне внутренних и наружных сонных артерий. Выявлено, что увеличение показателя толщины комплекса интима-медиа общих сонных артерий является при коморбидном течении ХОБЛ и абдоминальном ожирении независимым фактором риска сердечно-сосудистых катастро $\phi$ и прогрессирования кардиоваскулярной патологии. Ранняя диагностика и коррекция изменений гемодинамики в сонных артериях и метаболических нарушений позволит своевременно предотвратить неблагоприятные последствия сосудистых осложнений данной коморбидной патологии.

Ключевые слова: хроническая обструктивная болезнь легких, атеросклеротический процесс, сонные артерии, абдоминальное ожирение. 
низкой плотности (ЛПнП), холестерина липопротеинов высокой плотности (ЛПВП), триглицеридов (ТГ). Интерпретация выраженности симптомов проводилась по модифицированному вопроснику критериев тяжести одышки Британского медицинского совета Medical Research Council Scale (mMRC) и тесту оценки ХОБЛ COPD Assessment Test (САT). Переносимость физической нагрузки оценивалась с помощью 6-минутной шаговой пробы. Толерантность к физическим нагрузкам рассчитывалась c помощью теста с 6-минутной ходьбой. Расстояние, пройденное в течение 6 минут, измеряли в метрах и сравнивали с должным показателем, рассчитанным по формуле [10]: $(2,81 \times$ рост $)+(0,79 \times$ возраст) $-28,5$. Процент насыщения крови кислородом ( $\left.\mathrm{SpO}_{2}\right)$ определяли с помощью пульсоксиметра. Рассчитывали индекс курения по формуле: число выкуриваемых сигарет в день х стаж курения (годы)/20. Изучение гемодинамических показателей сонных артерий проведено методом ультразвукового дуплексного сканирования общих сонных артерий, внутренних сонных артерий и наружных сонных артерий на аппарате Mindray DC-6. B качестве маркера атеросклеротического процесса определялась толщина комплекса интима-медиа правой и левой общих сонных артерий (КИМ OCA). Для изучения КИМ общие сонные артерии сканировали в В-режиме с цветным допплеровским определением потока. Нормой считали КИМ<0,8 мм, утолщением КИМ $\geq 0,8$ мм. Критерием атеросклеротической бляшки считали локальное утолщение КИМ $\geq 1,3$ мм $[2,11]$. Для статистической обработки полученного материала использовали параметрические и непараметрические методы. С помощью одновыборочного теста Шапиро-Уилка уточняли, подчиняется ли данная выборка нормальному закону распределения. В том случае, если полученные в ходе обработки статистического материала данные подчинялись указанному тесту, применяли метод параметрического статистического анализа (критерий Стьюдента) для сравнения количественных характеристик изучаемых групп. Принимали во внимание уровень значимости $(p)<0,05$. Метод Пирсона применяли для определения коэффициента корреляции.

\section{Результаты исследования и их обсуждение}

Артериальная гипертензия (АГ) । степени выявлена у 11 больных (17,5\%), АГ ІІ степени - у 7 больных (11,1\%), АГ ІІІ степени - у 8 пациентов (12,7\%). Отягощенный наследственный анамнез по сахарному диабету выявлен у 18 больных (28,5\%). Сахарный диабет 2 типа при дообследовании впервые выявлен у 6 больных $(9,5 \%)$, нарушенная толерантность к глюкозе - у 10 пациентов (15,9\%), нарушенная гликемия натощак диагностирована у 5 больных (7,9\%). Сывороточное содержание общего холестерина в опытной группе составило 6,4士0,6 ммоль/л (в контрольной

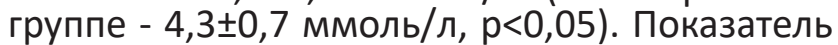
ТГ был равен 2,6士0,09 ммоль/л (в контрольной

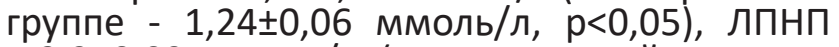
- 3,2士0,09 ммоль/л (в контрольной группе -

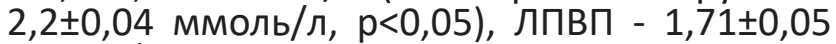

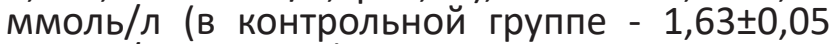
ммоль/л, $p>0,05)$. Индекс атерогенности

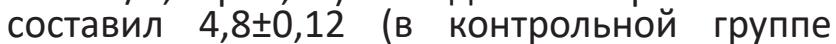

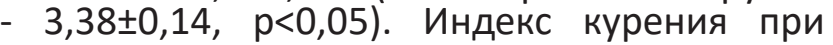
ХОБЛ составил 43,5 $\pm 19,4$ пачко-лет, при сочетанном течении ХОБЛ - 52,3 26,5 пачколет. У пациентов с коморбидным течением ХОБЛ наблюдалась большая степень выраженности клинических симптомов основного заболевания по сравнению с больными ХОБЛ без абдоминального ожирения. По данным количественной оценки степени тяжести одышки по шкале $\mathrm{mMRC}$ среднее значение выраженности одышки у

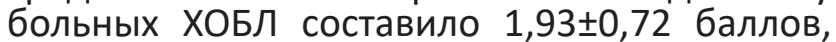
при коморбидном течении ХОБЛ имело

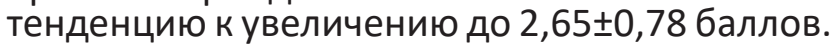
Интересно отметить, что при проведении

\title{
CORRELATION OF HEMODYNAMICS OF CAROTID ARTERIES IN CHRONIC OBSTRUCTIVE PULMONARY DISEASE WITH METABOLIC SYNDROME COMPONENTS
}

\section{O.A. Tanchenko, S.V. Naryshkina}

FSBEI HE the Amur state medical Academy of the Ministry of Public Health of Russia, Blagoveshchensk

\begin{abstract}
The article reviews the study of features of carotid artery hemodynamics in patients with chronic obstructive pulmonary disease (COPD) comorbidities and abdominal obesity. It is interesting to note that in the case of COPD with comorbidities there is a more pronounced increase in the resistance index at the level of the internal and external carotid arteries. It has been established that the increase in the carotid intimal medial thickness of the common carotid arteries in patients with COPD comorbidities and abdominal obesity is an independent risk factor for cardiovascular disasters and the progression of cardiovascular pathology. Early diagnostics and correction of changes in hemodynamics of the carotid arteries and metabolic disorders will allow timely prevention of adverse consequences of vascular complications of this comorbid pathology.
\end{abstract}

Key words: chronic obstructive pulmonary disease, atherosclerotic process, carotid arteries, abdominal obesity. 
Таблица 1. Клиническая характеристика пациентов в исследуемых группах

\begin{tabular}{|c|c|c|c|c|}
\hline \multirow[t]{2}{*}{ Показатели } & \multicolumn{4}{|c|}{ Исследуемые группы } \\
\hline & 1 группа & 2 группа & 3 группа & $\mathrm{p}$ \\
\hline Возраст, годы & $51,12 \pm 3,24$ & $52,43 \pm 2,06$ & $48,2 \pm 3,8$ & $\begin{array}{l}\mathrm{p} 1-2>0,05 \\
\mathrm{p} 1-3>0,05 \\
\mathrm{p} 2-3>0,05\end{array}$ \\
\hline Стаж курения, лет & $29,21 \pm 5,3$ & $21,86 \pm 4,8$ & 0 & $\begin{array}{l}\mathrm{p} 1-2>0,05 \\
\mathrm{p} 1-3<0,05 \\
\mathrm{p} 2-3<0,05\end{array}$ \\
\hline ИМТ, кг/м2 & $32,43 \pm 3,12$ & $23,63 \pm 2,28$ & $24,94 \pm 3,8$ & $\begin{array}{l}\text { p } 1-2<0,05 \\
\text { p } 1-3<0,05 \\
\text { p } 2-3>0,05\end{array}$ \\
\hline $\mathrm{SaO} 2$ & $95,27 \pm 2,8$ & $96,25 \pm 2,8$ & $98,31 \pm 1,03$ & $\begin{array}{l}\text { p1-2>0,05 } \\
\text { p1-3<0,05 } \\
\text { p2-3 }-30,05\end{array}$ \\
\hline $\begin{array}{l}\text { Глюкоза крови натощак, } \\
\text { ммоль/л }\end{array}$ & $7,11 \pm 1,64$ & $5,23 \pm 1,81$ & $5,18 \pm 1,61$ & $\begin{array}{l}\text { p1-2<0,05 } \\
\text { p1-3<0,05 } \\
\text { p2-3 }-30,05\end{array}$ \\
\hline $\begin{array}{l}\text { Артериальное давление } \\
\text { сист., мм рт. ст. }\end{array}$ & $151,31 \pm 3,8$ & $121,27 \pm 3,8$ & $117,2 \pm 2,8$ & $\begin{array}{l}\text { p1-2<0,05 } \\
\text { p1-3<0,01 } \\
\text { p2-3>0,05 }\end{array}$ \\
\hline $\begin{array}{l}\text { Артериальное давление } \\
\text { диаст., мм рт. ст. }\end{array}$ & $92,23 \pm 3,31$ & $65,23 \pm 2,67$ & $61,4 \pm 1,8$ & $\begin{array}{l}\text { p1-2<0,05 } \\
\text { p1-3<0,01 } \\
\text { p2-3>0,05 }\end{array}$ \\
\hline $\begin{array}{l}\text { Тест 6-мин. ходьба - } \\
\text { 6МШТ, м }\end{array}$ & $346,81 \pm 11,8$ & $457,21 \pm 13,85$ & $462 \pm 14,82$ & $\begin{array}{l}\text { p1-2>0,05 } \\
\text { p1-3<0,05 } \\
\text { p2-3>0,05 }\end{array}$ \\
\hline Инсулин, мкЕД/мл & $16,47 \pm 2,18$ & $8,26 \pm 1,53$ & $6,82 \pm 1,03$ & $\begin{array}{l}\text { p1-2<0,05 } \\
\text { p1-3<0,05 } \\
\text { p2-3>0,05 }\end{array}$ \\
\hline ИИР & $7,23 \pm 1,08$ & $2,4 \pm 0,32$ & $2,2 \pm 0,71$ & $\begin{array}{l}\text { p1-2<0,05 } \\
\text { p1-3<0,05 } \\
\text { p2-3>0,05 }\end{array}$ \\
\hline (ФНО- $\alpha)$, пг/мл & $14,3 \pm 1,91$ & $10,37 \pm 1,24$ & $5,2 \pm 0,94$ & $\begin{array}{l}\text { p1-2<0,05 } \\
\text { p1-3<0,05 } \\
\text { p2-3<0,05 }\end{array}$ \\
\hline $\begin{array}{l}\text { Эндотелин- } 1, \\
\text { фмоль/мл }\end{array}$ & $4,81 \pm 1,37$ & $2,24 \pm 1,64$ & $1,27 \pm 0,0$ & $\begin{array}{l}\text { p1-2<0,05 } \\
\text { p1-3<0,05 } \\
\text { p2-3>0,05 }\end{array}$ \\
\hline
\end{tabular}

Примечание: p1-2 - уровень значимости различий между 1-й и 2-й группами; р1-3 - уровень значимости различий между 1-й и 3-й группами; р2-3 - уровень значимости различий между 2-й и 3-й группами.

оценочного теста САТ на качество жизни при сочетанном течении ХОБЛ и абдоминального ожирения выявлено достоверное повышение оценочного показателя выше $27,2 \pm 3,74$ баллов

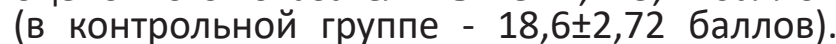
При выполнении 6-минутного шагового теста толерантность к физической нагрузке (6МШТ) в группе больных с коморбидным течением ХОБЛ была достоверно ниже, чем в контрольной группе. При коморбидном течении ХОБЛ и абдоминальном ожирении выявлено значимое повышение ИИР (таблица 1). Показатель КИМ правой и левой ОСА у пациентов с коморбидным течением ХОБЛ составил соответственно 1,04士0,02 мм и

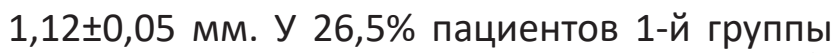
выявлено повышение уровня эндотелина-1, являющегося мощным вазоконстрикторным фактором, по сравнению с 2-й, 3-й группами. Интересно отметить, что при коморбидном течении ХОБЛ выявлено более выраженное повышение показателей индекса резистентности сонных артерий. Так, на уровне правой и левой внутренней сонных артерий данный показатель составлял

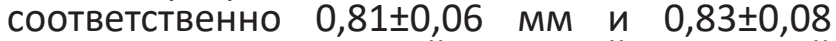
мм, на уровне правой и левой наружной сонных артерий данный показатель

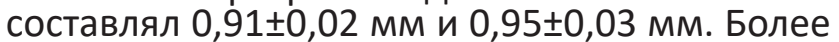
выраженный показатель толщины комплекса 
интима-медиа ОСА при наличии АГ при коморбидности ХОБЛ наряду с повышением показателей индекса резистентности сонных артерий можно объяснить воздействием высокого артериального давления на растяжение артериальной стенки с последующим усугублением данного процесса атеросклерозом. При изучении корреляционных взаимоотношений нами выявлены положительные взаимосвязи при коморбидном течении ХОБЛ между индексом инсулинорезистентности и показателем толщины комплекса интима-медиа общих сонных артерий и уровнем ТГ (соответственно, $r=0,93 ; p<0,01$ и $r=0,82 ; p<0,05)$, являющиеся гемодинамическим признаком атеросклеротического поражения сосудов при коморбидности ХОБЛ и абдоминальном ожирении.

\section{Выводы}

Таким диагностика нарушений й использованием метода ультразвукового дуплексного сканирования сонных артерий и комплексный подход к коррекции гемодинамических показателей, инсулинорезистентности, метаболических изменений у пациентов с ХОБЛ, ассоциированной с абдоминальным ожирением, могут способствовать улучшению функцииэндотелия иснижениюриска развития и прогрессирования сердечно-сосудистых катастроф при данной коморбидной патологии.

\section{Литература}

1. Авдеев С.Н. Можно ли улучшить прогноз у больных хронической обструктивной болезнью легких? // Пульмонология. 2015. Т. 25. №4. С. 469-476.

2. Вертинская Н.В. Влияние эндотелиальной дисфункции на гемодинамические изменения в малом круге кровообращения у больных с ХОБЛ // Дальневосточный медицинский журнал. 2008. №2. С. 11-13.

3. Гайнитдинова В.В., Бакиров А.Б., Ахметзянова Э.Х. Артериальная ригидность периферических сосудов у пациентов с хронической обструктивной болезнью легких и при ее сочетании с артериальной гипертензией // Казанский медицинский журнал. 2013. Т. 94. №6. С. 808-812.

4. Игнатова Г.Л., Антонов В.Н., Родионова O.В. Нарушение функции внешнего дыхания при сочетанном течении хронической обструктивной болезни легких и ишемической болезни сердца // Consilium Medicum. 2014. Т. 16. №11. С. 28-32.

5. Кароли Н.А., Ребров А.П. Жесткость артерий у больных хронической обструктивной болезнью легких // Терапевтический архив. 2012. T. 84. №3. С. 12-16.

6. Макарова М.А., Авдеев С.Н. Артериальная ригидность и эндотелиальная дисфункция у больныххроническойобструктивнойболезнью легких // Пульмонология. 2011. №4. С. 109-
117.

7. Танченко О.А., Нарышкина С.В., Решетникова Л.К. Особенности иммунного статуса у больных с метаболическим синдромом // Дальневосточный медицинский журнал. 2014. №2. C. 20-23.

8. Танченко О.А., Нарышкина С.В. Клинические особенности коморбидного течения хронической обструктивной болезни легких и метаболического синдрома // Материалы VII съезда врачей пульмонологов Сибири и Дальнего Востока / под общей редакцией академика РАН В.П. Колосова. Благовещенск, 2017. с. 199-202.

9. Танченко О.А., Нарышкина С.В. Клинико-функциональные особенности артериальной ригидности при сочетанной кардиопульмональной патологии // Бюллетень физиологии и патологии дыхания. 2018. Выпуск 67. С. 83-92.

10. Чикина С.Ю. Роль теста с 6-минутной ходьбой в ведении больных с бронхолегочными заболеваниями // Практическая пульмонология. 2015. Выпуск 4. C. 34-38.

11. Hodis H.N., Mask W.J., Labree L. The role of carotid arterial intima-media thickness in predicting clinical coronary events // Annals of Internal Medicine. 1998. Vol. 128. P. 262-269.

\section{Статья поступила в редакцию 16.10.2019}

\section{Координаты для связи}

Танченко Ольга Анатольевна, к.м.н., доцент кафедры факультетской и поликлинической терапии ФГБОУ ВО Амурская ГМА Минздрава россии. E-mail: tamaninao@gmail.com

Нарышкина Светлана Владимировна, д.м.н., профессор, заведующая кафедрой факультетской и поликлинической терапии ФГБОУ ВО Амурская ГМА Минздрава России.

Почтовый адрес ФГБОУ ВО Амурская ГМА Минздрава России: 675000, Амурская область, г. Благовещенск, ул. Горького, 95. E-mail: AmurSMA@AmurSMA.su, science.dep@ AmurSMA.su 